\title{
Bovine alpha-1 acid glycoprotein can reduce the chemotaxis of bovine monocytes and modulate CD18 expression
}

\author{
Cristina LeCCHI $^{1}$, Fabrizio CeCILIANI ${ }^{1 *}$, Sergio BernasConi ${ }^{2}$, \\ Federica FranCIOSI ${ }^{3}$, Valerio BRONZO ${ }^{1}$, Paola SARTORELLI ${ }^{1}$ \\ ${ }^{1}$ Dipartimento di Patologia Animale, Igiene e Sanità Pubblica Veterinaria, Facoltà di Medicina Veterinaria, \\ Università degli Studi di Milano, Italy \\ ${ }^{2}$ Istituto di Ricerche Farmacologiche Mario Negri, Italy \\ ${ }^{3}$ Dipartimento di Scienze Animali, Facoltà di Medicina Veterinaria, Università degli Studi di Milano, Italy
}

(Received 12 February 2008; accepted 20 June 2008)

\begin{abstract}
The acute phase protein $\alpha_{1}$-acid glycoprotein (AGP - Orosomucoid) is a lipocalin with immunomodulatory functions. The present study provides evidence that the plasma glycoforms of AGP inhibit the migration of bovine monocytes in response to classical chemoattractants. The inhibition is specific, since neutrophils are apparently not affected. To investigate the molecular basis of this finding, the expression of the molecules mostly involved in chemotaxis, including CD18, CD11b and CD47 was studied. It was found that the incubation of activated monocytes with acute phase concentration of AGP $(0.9 \mathrm{mg} / \mathrm{mL})$ induces a down-regulation of CD18, and has no apparent influence on CD11b and CD47. RT-PCR expression studies on CD18, CD11b and CD47 mRNA revealed that AGP treatment does not modify the expression rate of these genes. Since AGP treatment is related to a down-regulation of CD18 on the surface of the monocytes, the authors suggest that one of its possible functions consists in specifically reducing the firm adhesion phase of bovine monocytes to the endothelium.
\end{abstract}

alpha-1 acid glycoprotein / acute phase protein / CD18 / monocytes / chemotaxis

\section{INTRODUCTION}

Inflammation is a crucial response to tissue injury and host defences against invading microbes and tissue damage. An affected tissue accumulates leukocytes, which contribute to the inflammatory response by secreting cytotoxic and pro-inflammatory compounds, and by activating their phagocytic activity together with targeted attacks against foreign agents. The control of leukocyte efflux from the circulation, partially mediated by endothelial and leukocyte adhesion receptors, is important in regulating inflammation [21, 40]. A typical leukocyte chemotaxis consists of different phases: (i) tethering or capturing;

\footnotetext{
* Corresponding author: fabrizio.ceciliani@unimi.it
}

(ii) rolling; (iii) activation and (iv) firm adhesion. This sequence is regulated by several members from different families of cell adhesion proteins [32].

Firm adhesion of rolling leukocytes is mediated by members of the $\beta_{2}$ integrin family, which bind to intercellular adhesion molecules (ICAM) as well as to several soluble proteins, many of them being involved in inflammation. The integrins are heterodimers composed of non covalently associated $\alpha$ - and $\beta$-subunits. Eight subfamilies have been identified so far, each of which is characterized by a $\beta$-chain which differs from $\beta$-chains of the other subfamilies. The $\beta_{2}$ subfamily is characterized by the common $\beta_{2}$-subunit, CD18, linked to a unique 
$\alpha$-subunit. At present four $\beta_{2}$ integrins have been identified: CD11a/CD18 (LFA-1), CD11b/CD18 (MAC-1), CD11c/CD18 (p150/95) and CD11d/CD18 [15]. The involvement of the CD18 subunit in chemotaxis has been evidenced in humans and bovines by leukocyte adhesion deficiency (LAD). This phagocytic disease originates from mutations in the CD18 gene, which predisposes to life-threatening infections, caused by impaired intravascular adhesion, transendothelial migration, phagocytosis and target cell killing [2, 24].

CD47 (also known as integrin-associated protein or IAP) is an immunoglobulin superfamily member involved in leukocyte transmigration across the epithelia and endothelia. CD47 can modulate cell adhesion, cooperating with $\beta_{2}$ integrins $C D 11 b / C D 18$, and subsequent migration stages, resulting in rapid opening and closing of tight junctions to allow the passage of cells and the preservation of the epithelial barrier [26, 29]. CD47 is ubiquitously expressed on the plasma membrane [30], and anti-CD47 antibodies have been shown to potently inhibit neutrophil transmigration [22]. The presence and importance of CD47 in the migration of bovine neutrophils (PMN) were recently demonstrated by Lamote et al. [20].

Pro-inflammatory cytokines produced by leukocytes and endothelial cells during inflammation induce a reorganization of the gene expression pattern of hepatocytes, thus causing an up-regulation of the synthesis of a family of structurally unrelated proteins, the Acute Phase Proteins (APP). From a clinical perspective, alpha-1 acid glycoprotein (AGP) acts as a minor APP in humans and domestic animals, since its concentration is increased up to 3-5 fold during inflammation $[16,27]$. AGP is mainly produced by hepatic cells: extra-hepatic expression has even been reported in other tissues, such as in white blood cells, including cultured human monocytes [25,31], and in resting or activated polymorphonuclear leukocytes, all able to develop an immunological barrier providing a rapid defence against additional damage caused by inflammation $[6,27,28,38]$. While being one of the most important binding proteins in plasma [17], AGP also features several immunomodulatory functions [16], such as, for example, the stimulation of human monocytes to release pro- and anti-inflammatory cytokines [36], the inhibition of the chemotactic response of human neutrophils challenged with formyl-methionyl-leucyl-phenylalanine (fMLP) $[19,41]$ and the reduction of platelet aggregation [35]. Moreover, AGP is capable of protecting cells from apoptosis induced by inflammation [7-9]. In this study it was first hypothesized that AGP may modulate the chemotactic response of bovine defensive cells, including monocytes and polymorphonuclear cells. In the second part of the investigation, it was hypothesized that ideal targets of AGP activity were the surface molecules mostly involved in chemotactic migration, which include $\beta_{2}$-integrins and CD47. Before this study was carried out, the binding of AGP on the surface of monocytes and granulocytes was examined.

\section{MATERIALS AND METHODS}

\subsection{Materials}

\subsubsection{Reagents}

Zymosan A from Saccharomices cerevisiae, human recombinant IL-8 expressed in Escherichia coli, HEPES, EDTA, RPMI-1640, Red Blood Cell Lysing Buffer Hybri-Max ${ }^{\mathrm{TM}}$, Percoll, PBS without $\mathrm{Ca}^{2+}$ and $\mathrm{Mg}^{2+}$ and endotoxin-free water were purchased from Sigma-Aldrich Co. (St. Louis, MO, USA). Fetal Bovine Serum was provided by Biochrom AG (Berlin, Germany) and Ficoll 1077 by GE Healthcare Europe GmbH (Munich, Germany). Chemotaxis chamber and PVP-free polycarbonate filter were purchased from NeuroProbe ${ }^{\circledR}$ (Gaithersburg, MD, USA), Diff-Quick from Medion Diagnostics (Düdingen, Switzerland). Macs ${ }^{\circledR}$ Separation Columns and CD14 Microbeads were purchased from MiltenyiBiotech (Auburn, CA, USA), the RNeasy Mini Kit from Qiagen GmbH (Hiden, Germany), iScript ${ }^{\mathrm{TM}}$ cDNA Synthesis Kit and SYBR ${ }^{\circledR}$ Green mix from Biorad (Hercules, CA, USA).

AGP was obtained from healthy bovine serum following the chromatographic purification 
protocol previously established [7]. The final endotoxin level was measured using Limulus amebocyte lysate (LAL) (BioWhittaker, Walkersville, MD, USA). RhIL-8 was reconstituted in endotoxin-free water. Before use, ZAS was passed through a $0.22 \mu \mathrm{m}$ filter provided by Millipore (Billerica, MA, USA). Chromatin DNA stained DAPI was purchased from Molecular Probes ${ }^{\circledR}$ Europe BV (Leiden, Netherlands) and anti-fade medium from Vectashild (Burilngame, CA, USA).

Mouse anti-human CD47 (clone BRIC 126), which cross reacts with bovine CD47 [20], mouse anti-bovine $\mathrm{CD} 11 \mathrm{~b}$ (clone $\mathrm{CC} 126$ ) and their irrelevant control mouse antibody $\operatorname{IgG} 2 \mathrm{~B}$; mouse anti-canine CD18 (clone CA1.4E9), which cross reacts with bovine $\mathrm{CD} 18$ [3], and its irrelevant control mouse antibody IgG1, secondary antibody polyclonal rabbit anti-mouse IgG-FITC were purchased from Serotec (Oxford, UK) and resuspended in endotoxin-free PBS; goat antimouse IgG1-FITC IgG2b-PE were purchased from Santa Cruz Biotechnology ${ }^{\circledR}$ (Santa Cruz, CA, USA). The maximal inhibitory dose of each antibody was determined in initial dose-response experiments.

Polyclonal rabbit anti-bovine AGP was used as described [7]; the secondary antibody donkey anti-rabbit IgG-FITC was purchased from Jackson Immunoresearch lab (West Grove, PA, USA).

\subsubsection{Source and purification of monocytes and polymorphonuclear cells from bovine blood}

Bovine monocyte $\left(\mathrm{CD} 14^{+}\right.$cells) isolation was carried out as previously described [7] with some modifications. Clinically healthy multiparous lactating cows (Holstein Friesians) between three and eight years of age, and between four and ten weeks after calving were used for blood collection. Blood was collected by jugular venipuncture into sterile tubes containing $3.2 \%$ sodium citrate as an anticoagulant and was processed within one hour of collection. Buffy coat, obtained by centrifugation at $1260 \times g$ for $30 \mathrm{~min}$ at room temperature, was diluted 1:5 (vol/vol) in PBS with $2 \mathrm{mM}$ EDTA, and $10 \mathrm{~mL}$ of this solution were overlaid on $3 \mathrm{~mL}$ Ficoll 1077 and centrifuged for $30 \mathrm{~min}$ at $1500 \times g$ at $4{ }^{\circ} \mathrm{C}$. Mononuclear cells were collected from the interface. The cells were resuspended in $50 \mathrm{~mL}$ PBS with $2 \mathrm{mM}$ EDTA and centrifuged for $7 \mathrm{~min}$ at $400 \times g$ at $4{ }^{\circ} \mathrm{C}$ in order to remove platelets. This step was repeated four times. Remaining red blood cells were lysed with Red Blood Cell Lysing Buffer Hybri-Max.

Monocyte $\left(\mathrm{CD} 14^{+}\right)$cell isolation was carried out using magnetic activated cellular sorting (MACS). Briefly, PBMC were incubated with anti-human CD14 labeled super-paramagnetic beads $\left(20 \mu \mathrm{L} / 10^{8}\right.$ cells) for $15 \mathrm{~min}$ at $4{ }^{\circ} \mathrm{C}$ and $\mathrm{CD} 14^{+}$cells were isolated from a MidiMacs column according to the manufacturer's instructions. The purity of the sorted cells $(>98 \%)$ was evaluated by flow cytometry. Cell viability, as determined by Trypan Blue exclusion, was $>95 \%$. The concentration of monocytes was adjusted to $1.5 \times 10^{6} / \mathrm{mL}$ in migration medium with $1 \%$ heat inactivated FBS (see below).

Bovine neutrophils were isolated as described [5,34] after partial modifications. Blood samples were collected from six cows as described above; samples containing less than $5 \%$ of eosinophils were used. Blood was centrifuged at $1000 \times \mathrm{g}$ for $30 \mathrm{~min}$ at $4{ }^{\circ} \mathrm{C}$; the plasma, buffy coat and top one-third of the red blood cell pellet were aspirated. The remainder of the pellet containing PMN was diluted 1:3 ( $\mathrm{vol} / \mathrm{vol}$ ) in cold PBS, gently layered on $10 \mathrm{~mL}$ Percoll $1.087 \mathrm{~g} / \mathrm{mL}$ and centrifuged at $400 \times g$ for $40 \mathrm{~min}$ at room temperature. After the removal of Percoll, the remaining red blood cells were removed by hypotonic lysis and neutrophils were washed four times with cold PBS. Cell viability, as determined by Trypan Blue exclusion, was $>95 \%$. The concentration of neutrophils was adjusted to $1.5 \times 10^{6} / \mathrm{mL}$ in migration medium with $10 \%$ heat inactivated FBS.

\subsubsection{Media}

The AGP and rhIL- 8 were diluted in migration medium (RPMI 1640 with $20 \mathrm{mM}$ HEPES and $1 \%$ or $10 \%$ heat inactivated FBS for monocytes and neutrophils respectively).

Bovine serum was activated with $15 \mathrm{mg} / \mathrm{mL}$ of Zymosan $\mathrm{A}$ at $37^{\circ} \mathrm{C}$ for $60 \mathrm{~min}$. The mixture was then incubated at $56^{\circ} \mathrm{C}$ for $30 \mathrm{~min}$ to destroy complement components with the exception of $\mathrm{C} 5 \mathrm{a}$. Zymosan particles were removed by centrifuging the mixture for $15 \mathrm{~min}$ at $1000 \times g$ at $4{ }^{\circ} \mathrm{C}$. The supernatant obtained was filtered through a $0.22 \mu \mathrm{m}$ filter membrane, stored at $-80^{\circ} \mathrm{C}$ and used within three months. For migration assay the ZAS stock solution was diluted 1:5 ( $\mathrm{vol} / \mathrm{vol})$ with migration medium. 
The cells were incubated in the presence of chemoattractants: ZAS was used for monocytes and either ZAS or rhIL-8 $(100 \mathrm{ng} / \mathrm{mL}$, final concentration) for neutrophils [43]. The activated cells were then cultured with two different concentrations of purified AGP: precisely at low concentration similarly to bovine plasma in healthy subjects $(0.3 \mathrm{mg} / \mathrm{mL})$, and at high concentration similarly to bovine plasma at acute phase reaction $(0.9 \mathrm{mg} / \mathrm{mL})$ [11, 37]. Monocytes and neutrophils were incubated at $37^{\circ} \mathrm{C}$ for $2 \mathrm{~h}$ and $30 \mathrm{~min}$, respectively.

All the experiments were carried out by running control samples in parallel, in which AGP was replaced by medium. After incubation, the cells were centrifuged at $500 \times g$ for $7 \mathrm{~min}$ at $4{ }^{\circ} \mathrm{C}$ and suspended in migration medium without chemoattractants and protein.

\subsection{Migration assay}

Cell migration was evaluated using a microchamber technique as previously described [12]. Twenty-seven microliters of chemoattractant solution or migration medium (with $1 \%$ or $10 \%$ heat inactivated FBS for monocytes and neutrophils respectively) were added to the lower wells of a 48 -well chemotaxis chamber. Assays were made in triplicate. A PVP-free polycarbonate filter $(5 \mu \mathrm{m}$ pore size) [42] was layered onto the wells and covered with a silicon gasket and the top plate. Fifty microliters of cell suspension $\left(1.5 \times 10^{6}\right.$ cells $\left./ \mathrm{mL}\right)$ were seeded in the upper chamber. The chamber was incubated at $37^{\circ} \mathrm{C}$ in $5 \% \mathrm{CO}_{2}$ for $75 \mathrm{~min}$ for neutrophils and for $105 \mathrm{~min}$ for monocytes. At the end of incubation, the filters were removed and stained with Diff-Quick and ten high-power oil-immersion fields were counted.

\subsection{Flow cytometry analysis}

Indirect cell staining was performed. Neutrophils and monocytes were incubated with saturating amounts of primary antibodies, mouse anti-human CD47 or its irrelevant control mouse antibody $\operatorname{IgG} 2 \mathrm{~b}$ to eliminate non specific binding; mouse anti-bovine $\mathrm{CD} 11 \mathrm{~b}$ or its irrelevant control mouse antibody $\operatorname{IgG} 2 \mathrm{~b}$ and mouse anti-canine CD18 or its irrelevant control mouse antibody IgG1. Isolated cells $\left(5 \times 10^{5}\right)$ were suspended in sterile PBS with $1 \%$ FBS and incubated with primary antibody for $30 \mathrm{~min}$ at $4{ }^{\circ} \mathrm{C}$. After incubation, cells were centrifuged at $500 \times g$ for $8 \mathrm{~min}$ at $4{ }^{\circ} \mathrm{C}$, washed twice with excess of cold PBS with $1 \%$ FBS and labeled for $30 \mathrm{~min}$ at $4{ }^{\circ} \mathrm{C}$ in the dark with secondary antibody polyclonal rabbit anti-mouse IgG-FITC for neutrophils and goat anti-mouse IgG1-FITC or IgG2b-PE for monocytes. The cells were then centrifuged at $500 \times g$ for $8 \mathrm{~min}$ at $4{ }^{\circ} \mathrm{C}$, washed, stabilized with $1 \%$ formalin in PBS and kept at $4{ }^{\circ} \mathrm{C}$ until flow cytometric analysis.

Cells $\left(1 \times 10^{4}\right.$ events) were analyzed on a FACS Calibur cytometry system (Becton Dickinson, Mountain View, CA, USA) calibrated with Calibrite beads (Becton Dickinson).

\section{4. mRNA expression}

Total RNA was extracted from stimulated monocytes using the RNeasy Mini Kit according to the manufacturer's protocol. The reverse transcription (RT) reaction was carried out on $1 \mu \mathrm{g}$ RNA using an iScript ${ }^{\mathrm{TM}}$ cDNA Synthesis Kit. The thermal profile was as protocol suggesting. Quantitative reactions were performed in $25 \mu \mathrm{L}$ of $\mathrm{SYBR}^{\circledR}$ Green mix and $400 \mathrm{nM}$ of CD47 primers (senseGCTGGACTACTGCTCACTGTC and antisenseGAGGACATCCCCATAGCTATC) and GAPDH primers (sense-GGCGTGAACCACGAGAAGTA TAA and antisense-CCCTCCACGATGCCAA AGT) and $450 \mathrm{nM}$ of $\mathrm{CD} 11 \mathrm{~b}$ primers (senseGAGGCACTGTGATGCTGTCC and antisenseGCCTGTCCCCATTCACATCC) and CD18 primers (sense-CCTCAATGGCATCACCGAGTC and antisense-TGACGAAGGGGAGCACCG). Each sample was tested in duplicate. In order to evaluate the PCR efficiency, series of dilution were prepared by performing fourfold serial dilution starting from the reference samples. The thermal profile used $\left(95^{\circ} \mathrm{C}\right.$ for $90 \mathrm{~s}, 50$ cycles of $95^{\circ} \mathrm{C}$ for $15 \mathrm{~s}$ and $60^{\circ} \mathrm{C}$ for $60 \mathrm{~s}$; for melting curve construction, $55^{\circ} \mathrm{C}$ for $60 \mathrm{~s}$ and 80 cycles starting to $55^{\circ} \mathrm{C}$ and increasing $0.5^{\circ} \mathrm{C}$ each $10 \mathrm{~s}$ ) was the same for each target gene. The results obtained were compared using the delta-delta Ct method [14].

\subsection{Immunocytochemistry studies related to AGP binding to bovine monocytes}

In order to verify if the activated bovine monocytes were capable of binding AGP on the membrane surface, $1.5 \times 10^{5}$ monocytes were stimulated for $2 \mathrm{~h}$ with or without ZAS and AGP $(0.3 \mathrm{mg} / \mathrm{mL}$ or $0.9 \mathrm{mg} / \mathrm{mL})$. The cells were 
centrifuged at $500 \times g$ for $8 \mathrm{~min}$ at $4{ }^{\circ} \mathrm{C}$, washed two times with cold sterile PBS in order to remove stimulation medium and stabilized with $1 \%$ formalin. The cells were allowed to settle on a glass slide and processed to assess AGP localization by immunofluorescence. After an incubation of $30 \mathrm{~min}$ at $26^{\circ} \mathrm{C}$ in non-sterile PBS containing $1 \% \mathrm{BSA}$ and $1 \%$ NDS (Normal Donkey Serum), the slides were incubated overnight at $4{ }^{\circ} \mathrm{C}$ with a polyclonal rabbit anti-bovine AGP $(17 \mu \mathrm{g} / \mathrm{mL}$ in DPBS) [9]. After the incubation, the samples were washed twice in PBS and stained with a fluorescein isothiocyanate (FITC) conjugated donkey anti-rabbit IgG antibody (1:200) for $30 \mathrm{~min}$ at $26^{\circ} \mathrm{C}$. Chromatin DNA was stained with DAPI $(0.05 \mu \mathrm{g} / \mathrm{mL}$ in PBS $)$.

As the control, the primary antibody against AGP was omitted from one slide for each experiment. All samples were mounted with an anti-fade medium and observed with a conventional epifluorescence microscope (Nikon, Eclipse E 600).

\subsection{Statistical analysis}

For all statistical procedures, mean and standard error of the mean values were computed using statistical software (SPSS 15.0, SPSS Inc., Chicago, USA). Different treatments were compared using a non parametric Wilcoxon test for paired samples. Statistical significance was accepted at $P<0.05$.

\section{RESULTS}

\subsection{The quality of AGP}

The protein that was used throughout all the experiments presented hereby was purified from blood as described in the Materials and Methods section. The endotoxin level in AGP used in the present study was $<0.05 \mathrm{ng} / \mathrm{mg}$ of protein, a value compatible with in vivo experiments with monocytes and neutrophils. Analysis of AGP by SDS-PAGE followed by Commassie Brilliant blue staining revealed (i) a single band of $\sim 43 \mathrm{kDa}$; and (ii) homogeneity in the protein fraction, used to perform all the experiments in this paper (data not shown).

\subsection{Effect of AGP on monocyte and neutrophil chemotaxis}

To determine whether AGP is involved in monocyte and neutrophil chemotaxis, freshly isolated bovine monocytes and neutrophils were stimulated with AGP at physiological $(0.3 \mathrm{mg} / \mathrm{mL})$ or acute phase $(0.9 \mathrm{mg} / \mathrm{mL})$ concentration for $2 \mathrm{~h}$ and $30 \mathrm{~min}$ respectively. The chemotactic media were subsequently tested for monocyte and neutrophil migration in a modified Boyden chamber assay, where the cells were allowed to migrate across a membrane. As positive control, ZAS only was used for monocytes, while either ZAS or rhIL-8 was employed for neutrophils (Fig. 1). The results show that the migration of monocytes was modified by AGP at both low and high concentrations: as shown in Figure 1A, monocyte migration rate was significantly reduced when the cells were pre-incubated with AGP at both low and high concentrations and chemotactic medium contained only ZAS $(P<0.01)$. Similar results were obtained when the pre-incubated cells migrated to the chemotactic medium including ZAS and AGP at physiological dose. A further decrease of migration was observed when high concentration of AGP was added to the chemotactic medium with ZAS $(P<0.001)$. No modification in neutrophil migration was observed when either ZAS or rhIL-8 (Fig. 1B) was used as challengers.

\subsection{Influence of AGP on CD11b, CD18 and CD47 expression on monocyte and neutrophil surface}

The expression of CD47 on the surface of bovine monocytes has not been under investigation so far, to the authors' best knowledge. In the present study, it was assessed by means of flow cytometry which resulted in a clear expression of CD47, as observed and shown in supplementary material (Fig. A available online only at www.vetres.org). The mean channel fluorescence (MCF) for CD47 was $220 \pm 36$ (mean \pm SEM) after subtraction of fluorescence associated with the autofluorescence, isotype matched control and secondary antibody control. The mean value for CD11b (positive control) was $638 \pm 100$ (mean \pm SEM).

Monocytes and neutrophils were treated with or without chemotaxis activator (ZAS 

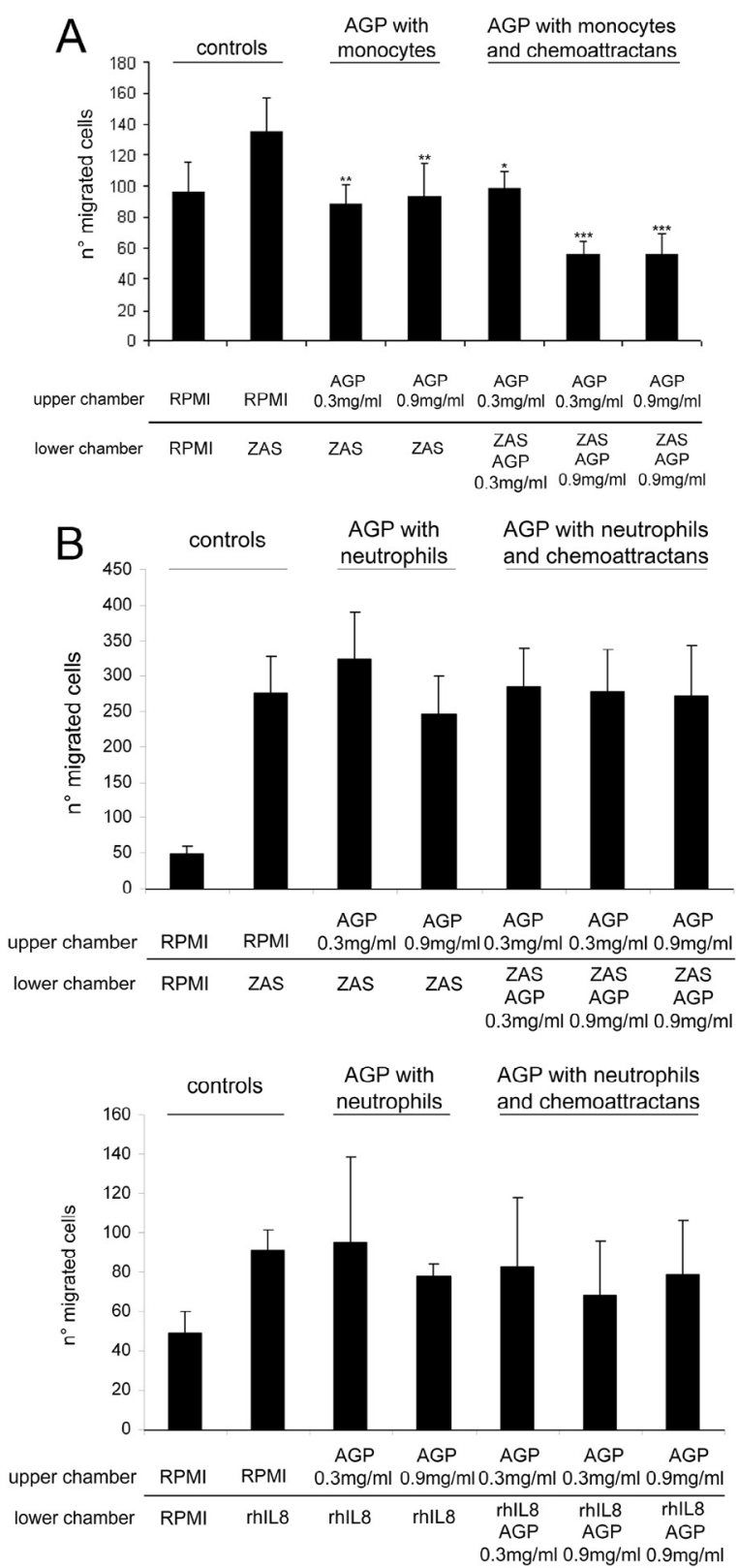

Figure 1. AGP effects on chemotactic monocyte and neutrophil response. (A) Bovine monocyte migration. Media with or without ZAS were used as positive or negative controls respectively. Each assay was carried out in triplicate. Data are means \pm SEM of eight independent experiments. The presence of physiological $(0.3 \mathrm{mg} / \mathrm{mL})$ and acute phase $(0.9 \mathrm{mg} / \mathrm{mL})$ doses of AGP in cell stimulation media significantly reduced to negative control level monocyte migration $\left({ }^{* *} P<0.01\right)$ when compared with positive controls. A migration reduction was also observed when AGP at physiological concentration was present in chemotactic medium with ZAS $\left({ }^{*} P<0.05\right)$. A higher migration reduction was observed when AGP at pathological concentration was present in chemotactic medium with ZAS $\left(^{* * *} P<0.001\right)$. (B) Bovine neutrophil migration towards ZAS or rhIL-8. Media with or without ZAS or rhIL-8 were used as positive or negative controls respectively. Each assay was carried out in triplicate. Data are means \pm SEM of six independent experiments. The AGP either at low $(0.3 \mathrm{mg} / \mathrm{mL})$ and high concentration $(0.9 \mathrm{mg} / \mathrm{mL})$ had no influence on the neutrophil migration.

Page 6 of 14 (page number not for citation purpose) 
for monocytes, and either ZAS or rhIL-8 for neutrophils) as positive and negative controls, respectively. AGP were added in the medium at low $(0.3 \mathrm{mg} / \mathrm{mL})$ or high $(0.9 \mathrm{mg} / \mathrm{mL})$ concentrations. Bovine monocytes exposed to AGP and ZAS for two hours revealed no significant influence as to the expression of CD11b and CD47 (Fig. 2), while monocytes treated with ZAS and AGP at high concentration demonstrated a decreased expression of CD18 $(P<0.05)$ compared with monocytes treated with ZAS only with the evident uprising of a CD18 negative monocyte population. In a series of seven experiments, AGP caused a $25 \%$ decrease of MCF and an $18 \%$ decrease of CD18 positive cells (\% gated). On the contrary, as seen in neutrophil migration experiments, neutrophils treated with rhIL-8/ZAS and AGP at high concentration showed no significant modification of CD47, CD11b and CD18 antigen surface expressions (Fig. 3).

\subsection{Expression of CD11b, CD18 and CD47 mRNA}

To investigate whether AGP could influence not only the surface expression of CD11b, CD18 and CD47 antigens, but also the corresponding mRNA levels in monocytes, the expression of genes was clearly established by quantitative real-time PCR analysis of monocyte cDNA. The relative quantification of CD11b, CD18 and CD47 mRNA between control cells and stimulated cells was performed by the delta-delta $\mathrm{Ct}$ method after normalization of the sample using the GAPDH gene as the housekeeping gene. The results are shown in Figure 4. In six different experiments, AGP did not cause any significant modification of CD11b, CD18 and CD47 gene expression.

\subsection{AGP binding to the surface of monocytes}

To investigate whether AGP binds directly to its target cells, both resting and stimulated monocytes were prepared and labeled for AGP immunoreactivity using the polyclonal anti-AGP antibody. The results are presented in Figure 5. ZAS-activated monocytes reveal a low, homogeneous staining, located on the surface of the cells. Treating monocytes with high concentration of AGP resulted in an evident increase of anti-AGP immunoreactivity, thus suggesting that plasma AGP can bind to the surface of activated monocytes.

\section{DISCUSSION}

In this paper, we report for the first time that the acute phase protein $\alpha_{1}$-acid glycoprotein is able to reduce the chemotaxis of bovine monocytes when used at high concentrations, similar to those found in plasma during a systemic response to inflammation. Remarkably, this inhibitory activity is both dose-dependent, the physiological concentration of AGP having no effect on chemotaxis, and cell-specific, since it does not affect neutrophils. This result was not consistent with what was observed in humans whose AGP can reduce PMN migration capability in a dose-dependent way $[19,41]$.

Tissues react to injuries by a basic process, an acute inflammatory reaction that physiologically leads to repair and/or removal of the damaged tissues. Its hallmark consists in activating defensive cells hierarchically, whose sequence includes resident macrophages, migrated polymorphonuclear cells and, finally, intervening monocytes [31].

The whole process, aimed at reducing unnecessary damages to nearby tissues, including both the influx of defensive cells and their lifespan, has to be tightly regulated. So far several proteins fulfilling this role have been characterized; many belong to the non structurally related family of acute phase proteins, among them AGP.

The biological significance of the involvement of AGP in the regulation of monocyte chemotaxis should be seen in the background of the activity of AGP on monocytes.

The so called mononuclear-phagocyte system plays a pivotal role in the inflammatory environment. Tissue resident macrophages are critical in triggering the inflammatory sequence by removing pathogens and producing pro-inflammatory cytokines. In a second 

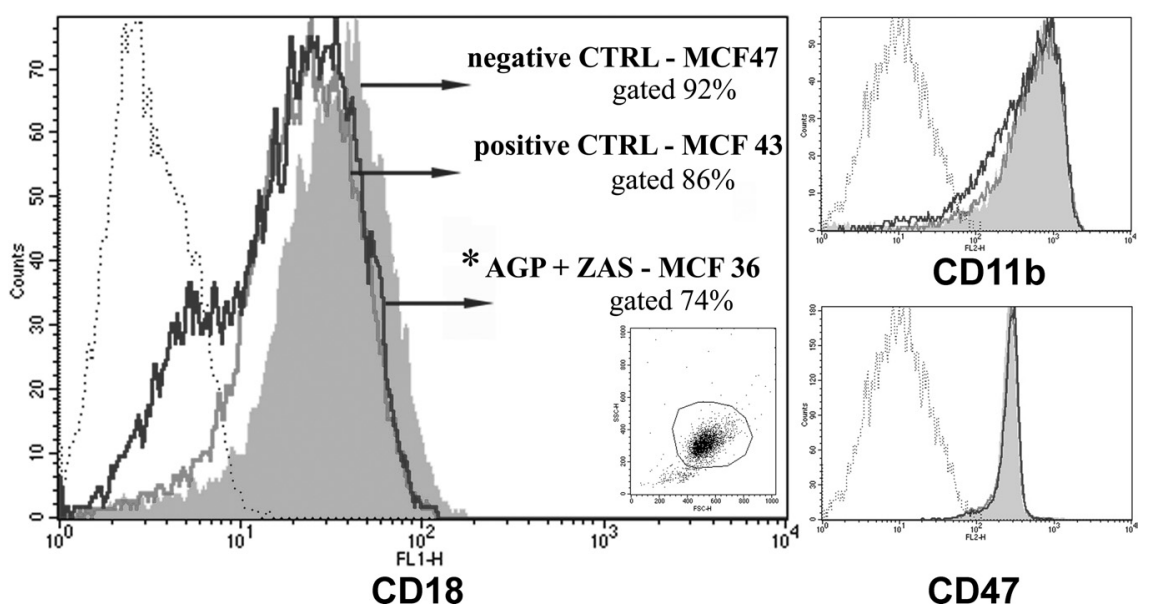

Figure 2. Flow cytometry analysis of AGP influence on monocyte antigens expression. Antigen surface expression in bovine monocytes exposed to AGP $(0.9 \mathrm{mg} / \mathrm{mL}, 2 \mathrm{~h})$ plus ZAS (black line) compared with cells treated with negative control (medium - solid histogram) and positive control (ZAS without AGP - grey line), as indicated by the arrows. Dotted line indicates irrelevant control antibody. ${ }^{*} P<0.05$. Values are expressed as Mean Channel Fluorescence (MCF). Stimulation with high AGP doses determines the formation of a population with a reduced CD18 expression on membranes. The CD11b and CD47 surface expression are not modulated by AGP. (A color version of this figure is available at www.edpsciences.org/vetres.)

inflammatory phase, intervening monocytes recruited from blood due to pro-inflammatory signaling - become crucial in the resolution phase of inflammation thanks to the production of anti-inflammatory cytokines as well as the elimination of polymorphonuclear cells and tissue debris. AGP targets several monocyte/macrophage functions during inflammation, including the up-regulation of the expression of anti-inflammatory cytokines [39] and the increasing of their lifespan by reducing their apoptosis rate [7]. Therefore, the main function of AGP in the inflammatory focus converges toward an overall anti-inflammatory function, which is carried out by attenuating tissue damages related to uncontrolled activation of cells involved in the inflammatory process. In fact, given the reduction of the monocyte chemotaxis by AGP, potentially it might also increase the lifespan of neutrophils in the inflammatory focus, but this seemingly pro-inflammatory activity is poorly consistent with the other activities of AGP identified so far.

The possibility that this anti-chemotactic activity of AGP is directed toward a specific

Page 8 of 14 (page number not for citation purpose) monocyte subpopulation should not be ruled out. Human monocytes have been further classified in different subsets, the $\mathrm{CD} 16^{-} / \mathrm{CCR} 2^{+}$ monocytes [44], which are recruited to tissues during inflammation, and $\mathrm{CD}_{16}{ }^{+} / \mathrm{CCR}^{-}$, which migrate into tissues irrespective of inflammatory stimuli. This latter population exhibits surface antigens that resemble those of tissue macrophages, and, coherently, shows a higher antigen presenting cell activity and pronounced pro-inflammatory cytokine pattern. It should be interesting to investigate whether the AGP activity is targeted toward a specific monocyte subset. Unfortunately, while described in all the species investigated so far, which include the pig, mouse, rat and, of course, humans, the presence of the $\mathrm{CD} 16^{+} / \mathrm{CD} 16^{-}$population in bovines has yet to be demonstrated, since, at least to our knowledge, anti-CD16 antibodies specific for bovine cells are not available.

The anti-chemotactic activity of AGP against monocytes may also be seen in relation with the decreasing of milk-resident macrophages during early post-partum [18, 23], since it was found that AGP increases its 

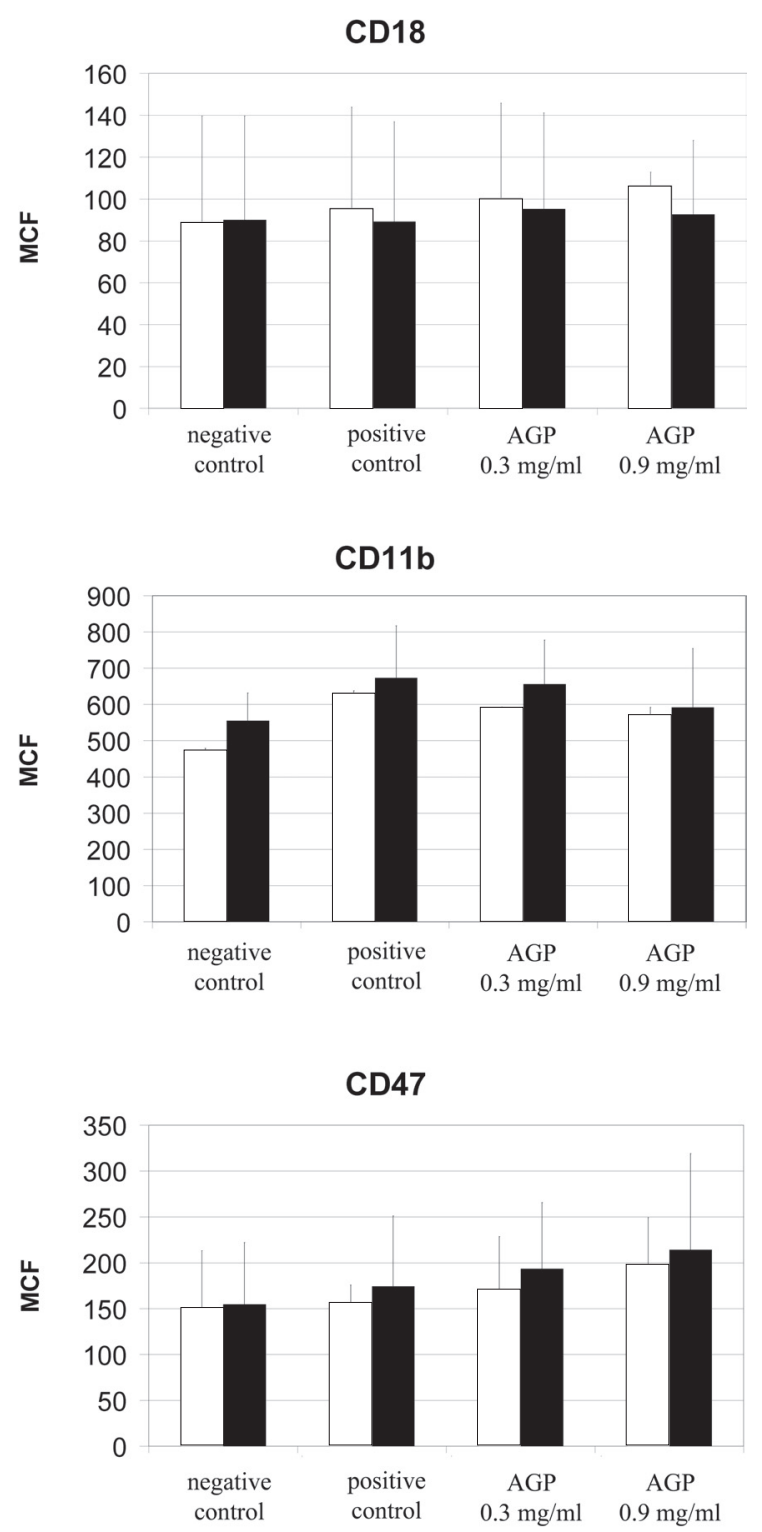

Figure 3. Flow cytometric analysis of AGP at acute phase concentration $(0.9 \mathrm{mg} / \mathrm{mL})$ plus rhIL- 8 or ZAS activation on CD47, CD18 and CD11b neutrophil surface expression. Positive controls were media with rhIL-8 or ZAS, negative control were media without rhIL- 8 or ZAS. AGP $0.3 \mathrm{mg} / \mathrm{mL}$, and AGP $0.9 \mathrm{mg} / \mathrm{mL}$ indicates treatment in which cells were co-incubated with AGP and respective challenger (white box: rhIL-8, black box: ZAS). Data are means \pm SEM of three independent experiments. No significant modifications were observed on antigen surface expressions shown as MCF values. 


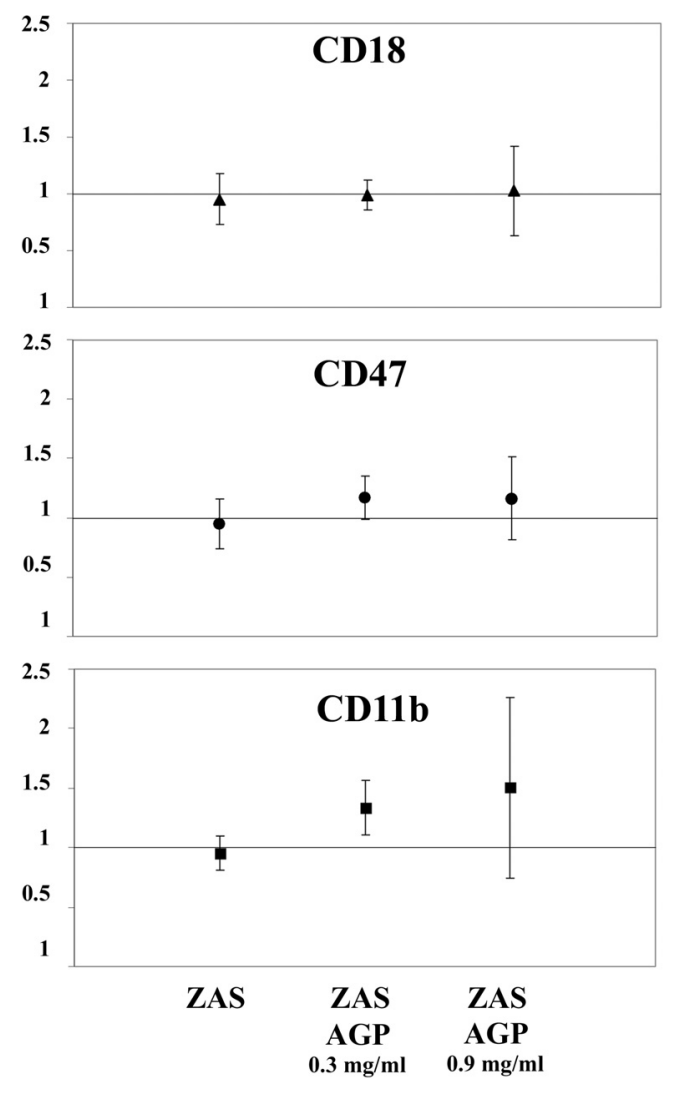

Figure 4. Relative CD11b, CD18 and CD47 gene expression in monocytes incubated with ZAS with or without AGP at $0.3 \mathrm{mg} / \mathrm{mL}$ or $0.9 \mathrm{mg} / \mathrm{mL}$ for 2 hours. The results were normalized using GAPDH as the housekeeping gene. Data are means of six independent experiments.

plasma level around peripartum [4]. Though interesting, this hypothesis must be carefully investigated, since it was reported that the expression of $\beta_{2}$-integrins on monocyte surface does not change during peripartum [10].

In an attempt to explain the downregulation of monocyte chemotaxis at the molecular level, it was found that AGP causes a lowering of the net number of CD18 molecules on the monocyte surface, thus inducing the uprising of a new population of $\mathrm{CD} 18^{-}$monocytes. No effect has been shown on the expression of the integrin $\mathrm{CD} 11 \mathrm{~b}$, the other twin component of MAC-1, as well as on $\mathrm{CD} 47$, a protein that can associate with and modulate the activity of several integrins [13].
The explanation of these two populations of $\mathrm{CD}_{18}{ }^{+}$and $\mathrm{CD} 18^{-}$is elusive.

Conceivably, the logic outcome of the down-regulation of CD18 should be the reduction of the adhesion phase in the transendothelial migration sequence. Yet, this hypothesis has to be definitely confirmed by experiments that include endothelial cells into the culture scaffold, such as those previously reported [33]. Therefore, since our Boyden chamber experimental model excludes the interaction of CD18 with the adhesion molecules exposed on the surface of activated endothelium, it can be hypothesized that there is at least another mechanism that reduces the migration of monocytes, and that is not 

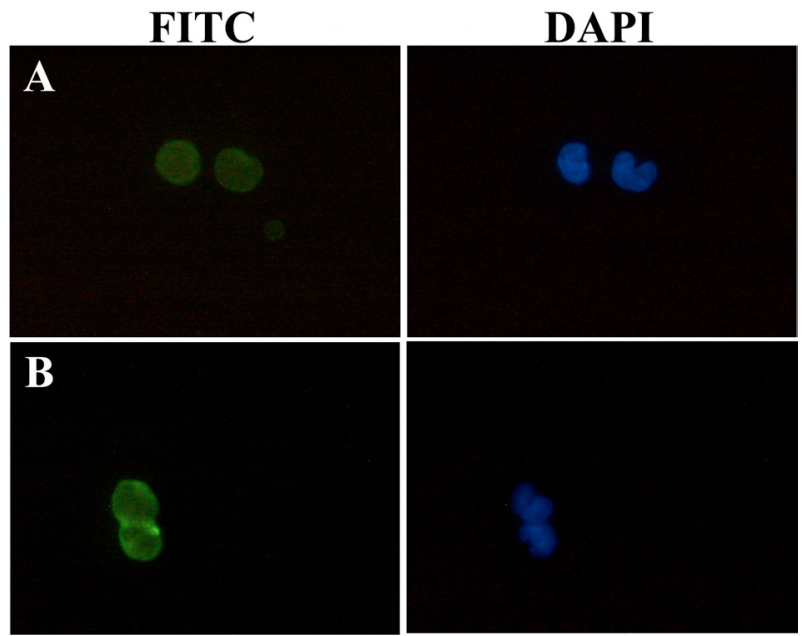

Figure 5. Direct binding of AGP to monocyte membrane after ZAS activation. Isolated monocytes treated for $2 \mathrm{~h}$ with ZAS (panel A) and ZAS with AGP $(0.9 \mathrm{mg} / \mathrm{mL})$ (panel B). Panel A: ZAS-stimulated monocytes (negative controls), immunostained with polyclonal rabbit anti-bovine AGP (27), as primary antibody, and donkey anti-rabbit-FITC, secondary antibody (left panel) and DAPI nuclear staining (right panel). Panel B: ZAS-AGP stimulated monocytes, immunostained with polyclonal rabbit anti-bovine AGP and donkey anti-rabbit-FITC (left panel) and DAPI nuclear staining (right panel). (A color version of this figure is available at www.edpsciences.org/vetres.)

related to the interaction of $\mathrm{CD} 18$-adhesion molecules.

Indeed, the down-regulation of integrins on the surface of the cells by AGP not only does imply the reduction of the adhesion of monocytes to endothelial cells, but also the downgrading of several other activities involving where MAC-1 integrin is involved, including the clustering and association with cytoskeletal and signaling complexes, such as MAPK and PI3P-kinases, or Rho family of GTPases [13]. The reduction of chemotaxis in our in-vitro model may be due to the downregulation of one, or more, integrin functions.

After cellular activation, the pattern of MAC-1 expression on the surface of monocytes follows two waves. The first one originates from the storage pools, and is mobilized from the secretory vesicles to the outer membrane of the cell within a few minutes after the first chemotactic signaling, inducing a 4- to 12-fold increase over the basal level of the integrins [1]. The second wave appears after 24-72 h, and is the result of newly synthesized integrins. Since RT-PCR expression studies on CD18, CD11b and CD47 mRNA ruled out any modification of the expression rate of these genes caused by AGP treatment, we can hypothesize that the activity of AGP is likely to be related to the direct interfering with the exocytosis of the first wave of integrins, rather than connected to the 'de novo' synthesis of the second wave.

Another possible mechanism of action of AGP should not be ruled out. As an immunocalin, AGP may fulfil both functions of binding protein and immunomodulatory molecule. The results presented in this paper demonstrate that when high concentration of AGP is added to the chemotactic medium, it further decreases the migration rate of monocytes. While no binding properties of AGP toward C5a have been reported, it can be hypothesized that AGP molecules bind ZAS-generated C5a. This activity could be explained by the lipocalin structure of AGP, which allows the protein to interact with 
more than 300 different molecules [7, 16]. Therefore, it is possible that a further possible mechanism of action of AGP is that of dampening the inflammation by sequestering some of the mediators, thus reducing their biological availability in the inflammatory environment.

It remains to be elucidated why this effect is not evident in neutrophils, but only in monocytes.

In conclusion, the results of this investigation report for the first time the inhibitory effect of chemotaxis of AGP on bovine monocytes, and indicate that acute phase concentrations of AGP reduce the expression of CD18 on monocyte surfaces.

This finding may suggest a regulatory role for AGP in specific trafficking of monocytes from blood to tissues, and contribute to understanding the regulatory function of acute phase protein overexpression on blood cell migration during acute inflammation. Further studies are necessary to characterize the sub-population of monocytes, in order to investigate whether the activity is directed toward a specific population of monocytes.

Acknowledgements. We are grateful to Prof. Gigliola Canepa for her valuable help in the final editing of the paper. This work was financed by Grant FIRST/2004 funded to Dr Ceciliani, and PRIN 2006 funded to Prof. Paola Sartorelli.

\section{REFERENCES}

[1] Al-Numani D., Segura M., Doré M., Gottshalk M., Up-regulation of ICAM-1, CD11a/CD18 and CD11c/CD18 on human THP-1 monocytes stimulated by Streptococchus suis serotype 2, Clin. Exp. Immunol. (2003) 133:67-77.

[2] Arnaout M.A., Leukocyte adhesion molecules deficiency: its structural basis, pathophysiology and implications for modulating the inflammatory response, Immunol. Rev. (1990) 114:145-180.

[3] Brodersen R., Bijlsma F., Gori K., Jensen K.T., Chen W., Dominguez J., et al., Analysis of the immunological cross reactivities of 213 well characterized monoclonal antibodies with specificities against various leucocyte surface antigens of human and 11 animal species Vet. Immunol. Immunopathol. (1998) 64:1-13.
[4] Cairoli F., Battocchio M., Veronesi M.C., Brambilla D., Conserva F., Eberini I., et al., Serum protein pattern durino cow pregnancy: Acute-phase proteins increase in peridpartum period, Electrophoresis (2006) 27:1617-1625.

[5] Carlson G.P., Kaneko J.J., Isolation of leukocytes from bovine peripheral blood, Proc. Soc. Exp. Biol. Med. (1973) 142:853-856.

[6] Ceciliani F., Pocacqua V., Lecchi C., Fortin R., Rebucci R., Avallone G., et al., Differential expression and secretion of $\alpha 1$-acid glycoprotein in bovine milk, J. Dairy Res. (2007) 74:374-380.

[7] Ceciliani F., Pocacqua V., Miranda-Ribera A., Bronzo V., Lecchi C., Sartorelli P., Alpha(1)Acid glycoprotein modulates apoptosis in bovine monocytes, Vet. Immunol. Immunopathol. (2007) 116:145-152.

[8] Daemen M., Heemskerk V.H., Vant'Veer C., Denerek G., Wolfs T., Vandenabeele P., Buurman W.A., Functional protection by acute phase proteins alpha(1)-acid glycoprotein and alpha(1)antitrypsin against ischemia/reperfusion injury by preventing apoptosis and inflammation, Circulation (2000) 102:1420-1426.

[9] De Vries B., Walter S.J., Wolfs T., Hochepied T., Räbinä J., Heeringa P., et al., Exogenous alpha1-acid glycoprotein protects against renal ischemiareperfusion injury by inhibition of inflammation and apoptosis, Transplantation (2004) 78:1116-1124.

[10] Diez-Fraile A., Duchateau L., Meyer E., Burvenich C., Expression of $\beta_{2}$-integrin on monocytes and blood polymorphonuclear leukocytes in the periparturient period in dairy cows, Can. J. Vet. Res. (2003) 67:235-238.

[11] Eckersall P.D., Young F.J., McComb C., Hogarth C.J., Safi S., Weber A., et al., Acute phase proteins in serum and milk from dairy cows with clinical mastitis, Vet. Rec. (2001) 148:35-41.

[12] Falk W., Goodwin R.H. Jr., Leonard E.J., A 48-well micro chemotaxis assembly for rapid and accurate measurement of leukocyte migration, J. Immunol. Methods (1980) 33:239-247.

[13] Giancotti F.G., Ruoslahti E., Integrin signalling, Science (1999) 285:1028-1032.

[14] Giulietti A., Overbergh L., Valckx D., Decallonne B., Bouillon R.., Mathieu C., An overview of real-time quantitative PCR: applications to quantify cytokine gene expression, Methods (2001) 25:386-401.

[15] Harris E.S., McIntyre T.M., Prescott S.M., Zimmerman G.A., The leukocyte integrins, J. Biol. Chem. (2000) 275:23409-23412.

[16] Hochepied T., Berger F.G., Baumann H., Libert C., Alpha(1)-acid glycoprotein: an acute phase protein

Page 12 of 14 (page number not for citation purpose) 
with inflammatory and immunomodulating properties, Cytokine Growth Factor Rev. (2003) 14:25-34.

[17] Israili Z.H., Dayton P.G., Human alpha-1glycoprotein and its interactions with drugs, Drug Metab. Rev. (2001) 33:161-235.

[18] Jensen D.L., Eberhardt R.J., Total and differential cell counts in secretions of the nonlactating bovine mammary gland, Am. J. Vet. Res. (1981) 42: 743-747.

[19] Lainé R., Couderc R., Roch-Arveiller M., Vasson M.P., Giroud J.P., Raichvarg D., Modulation of human polymorphonuclear neutrophil functions by alpha 1-acid glycoprotein, Inflammation (1990) 14:1-9.

[20] Lamote I., Meyer E., De Ketelaere A., Duchateau L., Burvenich C., Influence of sex steroids on the viability and CD11b, CD18 and CD47 expression of blood neutrophils from dairy cows in the last month of gestation, Vet. Res. (2006) 37:61-74.

[21] Ley K., The role of selectins in inflammation and disease, Trends Mol. Med. (2003) 9:263-268.

[22] Liu Y., Merlin D., Burst S.L., Pochet M., Madara J.L., Parkos C.A., The role of CD47 in neutrophil transmigration. Increased rate of migration correlates with increased cell surface expression of CD47, J. Biol. Chem. (2001) 276:40156-40166.

[23] McDonald J.S., Anderson A.J., Total and differential somatic cell counts in secretions of the noninfected bovine mammary gland: the peripartum period, Am. J. Vet. Res. (1981) 42:1366-1368.

[24] Nagahata H., Bovine leukocyte adhesion deficiency (BLAD): a review, J. Vet. Med. Sci. (2004) 66:1475-1482.

[25] Nakamura T., Board P.G., Matsushita K., Tanaka H., Matsuyama T., Matsuda T., Alpha 1-acid glycoprotein expression in human leukocytes: possible correlation between alpha 1-acid glycoprotein and inflammatory cytokines in rheumatoid arthritis, Inflammation (1993) 17:33-45.

[26] Parkos C.A., Colgan S.P., Liang T.W., Nusrat A., Bacarra A.E., Carnes D.K., Madara J.L., CD47 mediates post-adhesive events required for neutrophil migration across polarized intestinal epithelia, J. Cell Biol. (1996) 132:437-450.

[27] Petersen H.H., Nielsen J.P., Heegard P.M., Application of acute phase protein measurement in veterinary clinical chemistry, Vet. Res. (2004) 35:163-187.

[28] Poland D.C., García Vallejo J.J., Niessen H.W., Nijmeyer R., Calafat J., Hack C.E., et al., Activated human PMN synthesize and release a strongly fucosylated glycoform of $\alpha 1$-acid glycoprotein, which is transiently deposited in human myocardial infarction, J. Leukoc. Biol. (2005) 78:453-461.
[29] Rebres R.A., Kajihara K., Brown E.J., Novel CD47-dependent intercellular adhesion modulates cell migration, J. Cell. Physiol. (2005) 205:182-193.

[30] Reinhold M.I., Lindberg F.P., Plas D., Reynolds S., Peters M.G., Brown E.J., In vivo expression of alternatively spliced forms of integrin-associated protein (CD47), J. Cell. Sci. (1995) 108:3419-3425.

[31] Shibata Y., Tamura K., Ishida N., Cultured human monocytes, granulocytes and a monoblastoid cell line (THP-1) synthesize and secrete immunosuppressive acidic protein (a type of alpha 1-acid glycoprotein), Microbiol. Immunol. (1984) 28:99-111.

[32] Simon S.I., Green C.E., Molecular mechanics and dynamics of leukocyte recruitment during inflammation, Annu. Rev. Biomed. Eng. (2005) 7:151-185.

[33] Smits E., Cifrian E., Guidry A.J., Rainard P., Burvenich C., Paape M.J., Cell culture system for studying bovine neutrophil diapedesis, J. Dairy Sci. (1996) 79:1353-1360.

[34] Smits E., Burvenich C., Guidry A.J., MassartLeën A., Adhesion receptor CD11b/CD18 contributes to neutrophil diapedesis across the bovine blood-milk barrier, Vet. Immunol. Immunopathol. (2000) 73: $255-265$.

[35] Snyder S., Coodley E.L., Inhibition of platelet aggregation by alpha1-acid glycoprotein, Arch. Intern. Med. (1976) 136:778-781.

[36] Su S.J., Yeh T.M., Effects of alpha 1-acid glycoprotein on tissue factor expression and tumor necrosis factor secretion in human monocytes, Immunopharmacology (1996) 34:139-145.

[37] Tamura K., Yatsu T., Itoh H., Motoi Y., Isolation, characterization, and quantitative measurement of serum alpha 1-acid glycoprotein in cattle, Nippon Juigaku Zasshi (1989) 51:987-994.

[38] Theilgaard-Mönch K., Jacobsen L.C., Rasmussen T., Niemann C.U., Udby L., Borup R., et al., Highly glycosylated alpha1-acid glycoprotein is synthesized in myelocytes, stored in secondary granules, and released by activated neutrophils, J. Leukoc. Biol. (2005) 78:462-470.

[39] Tilg H., Vannier E., Vachino G., Dinarello C.A., Mier J.W., Anti-inflammatory properties of hepatic acute phase proteins: preferential induction of interleukin 1 (IL-1) receptor antagonist over IL-1 beta synthesis by human peripheral blood mononuclear cells, J. Exp. Med. (1993) 178:1629-1636.

[40] Ulbrich H., Eriksson E.E., Lindbom L., Leukocyte and endothelial cell adhesion molecules as targets for therapeutic interventions in inflammatory disease, Trends Pharmacol. Sci. (2003) 24:640-647.

[41] Vasson M.P., Roch-Arveiller M., Couderc R., Baguet J.C., Raichvarg D., Effects of alpha-1 acid 
Vet. Res. (2008) 39:50

glycoprotein on human polymorphonuclear neutrophils: influence of glycan microhetrogeneity, Clin. Chim. Acta (1994) 224:65-71.

[42] Worku M., Paape M.J., Filep R., Miller R., Effect of in vitro and in vivo migration of bovine neutrophils on binding and expression of Fc receptors for IgG2 and IgM, Am. J. Vet. Res. (1994) 55:221226.
C. Lecchi et al.

[43] Zerbe H., Schuberth H.J., Engelke F., Frank J., Klug E, Leibold W., Development and comparison of in vivo and in vitro models for endometritis in cows and mares, Theriogenology (2003) 60: 209-223.

[44] Ziegler-Heitbrock L., The CD14+ CD16+ blood monocytes: their role in infection and inflammation, J. Leukoc. Biol. (2007) 81:584-592. 